\title{
Perfloxacin and ciprofloxacin in the treatment of uncomplicated gonococcal urethritis in males
}

\author{
L L Cheong, R K W Chan, M Nadarajah
}

\begin{abstract}
Objective-To study the effectiveness of single-dose perfloxacin and ciprofloxacin in the treatment of uncomplicated gonococcal urethritis in males.

Setting-Department of STD Control, Kelantan Road, Singapore.

Method-160 male patients with uncomplicated gonococcal urethritis were assigned alternately to receive single oral doses of either perfloxacin $800 \mathrm{mg}$ or ciprofloxacin $250 \mathrm{mg}$.

Results-Of the perfloxacin group $98.5 \%$ (65/66 patients) and of the ciprofloxacin group $98.6 \%$ (74/75 patients) were cured of gonorrhoea. The rates of post-gonococcal urethritis were $64.3 \%$ and $67.3 \%$ in the perfloxacin and ciprofloxacin groups, respectively. Both drugs were well tolerated and reported side-effects were minor and transient. There was a high incidence of penicillinase-producing gonococci (32.3\%) and tetracycline resistant isolates with MIC $\geqslant 2 \mathrm{mg} / \mathrm{l}(99 \cdot 3 \%)$. High level tetracycline resistance (MIC $\geqslant 16 \mathrm{mg} / \mathrm{l}$ ) was found in $7 \cdot 4 \%$ of isolates. Conclusion-The drugs in the dosages studied may be recommended for firstline treatment of uncomplicated gonococcal urethritis in males in Singapore. However, the emergence of bacterial resistance to the fluoroquinolones in the literature calls for vigilance in the monitoring of antimicrobial susceptibility.
\end{abstract}

\section{Introduction}

The increasing incidence of penicillinase-producing Neisseria gonorrhoeae has spurred efforts the world over in search of alternatives to penicillin for treatment. The fluoroquinolones have been hailed as attractive drugs for this purpose as they can be administered orally, are highly bactericidal with minimal side-effects and possess a wide antibacterial spectrum. ${ }^{1}$ Several clinical studies have documented high cure rates of gonococcal infection with the use of fluoroquinolone antibiotics. ${ }^{2-6}$ In view of such encouraging findings, we felt it important to investigate the effectiveness of two readily available fluoroquinolones, perfloxacin and ciprofloxacin, in the eradication of $N$. gonorrhoeae infection in the local population.

Hospita

M Nadarajah

Address for correspondence: Dr Cheong Lai Leng, National Skin Centre, 1 Mandalay Rd, Singapore 1130.

Accepted for publication 27 March 1992

\section{Materials and method}

The study population comprised males, aged 18 years and above, with uncomplicated gono- mitted Diseases Clinic at the Kelantan Road Polyclinic between February and November 1990. Exclusion criteria included antibiotic therapy within the past seven days, known allergy to quinolones and renal, hepatic or haematological disorders. Verbal consent for participation in the study was obtained from all patients.

Urethral specimens were collected with sterile platinum loops and smears made for Gramstaining. A presumptive diagnosis of gonococcal urethritis was made when intracellular Gram-negative diplococci were found in the urethral smear. The diagnosis was confirmed on isolation of $N$. gonorrhoeae on culture. These patients were then assigned alternately to receive either perfloxacin $800 \mathrm{mg}$ or ciprofloxacin $250 \mathrm{mg}$, in single oral doses. They were scheduled to return for test of cure on the 4 th day and for screening for post-gonococcal urethritis on the 14th day. They were also advised to refrain from sexual intercourse and to report any adverse effects after taking the medication.

A negative culture for $N$. gonorrhoeae of a urethral specimen taken on the 4 th posttreatment day would indicate cure while a positive culture signified treatment failure. Post-gonococcal urethritis was defined as the presence of five or more pus cells per high power field in a Gram-stained urethral smear taken on the 14 th post-treatment day.

\section{Laboratory methods}

Urethral specimens were collected with sterile platinum loops and plated immediately onto modified Thayer-Martin culture media. The plates were incubated at $36^{\circ} \mathrm{C}$ in a $\mathrm{CO}_{2}$ enriched environment for 24 to 48 hours. Identification was by colonial appearance, oxidase test and Gram-stained microscopic appearance. Penicillinase production was tested for by the paper acidometric method described by Sng et al. ${ }^{7}$ Confirmed isolates were tested for susceptibility to perfloxacin or ciprofloxacin, penicillin, ampicillin, tetracycline, kanamycin and spectinomycin by the agar dilution method. ${ }^{\mathbf{8}}$ The susceptibilities were expressed as minimal inhibitory concentrations (MICs) to the various drugs.

\section{Results}

Clinical and laboratory results coccal urethritis attending the Sexually Trans-
A hundred and sixty men were enrolled in the study. Half the population was treated with perfloxacin and the other half with ciprofloxacin. Two patients treated with perfloxacin 
Table 1 Clinical and laboratory data of the study population

\begin{tabular}{|c|c|c|c|c|c|}
\hline & & \multicolumn{4}{|c|}{ Treatment } \\
\hline & & \multicolumn{2}{|c|}{ Perfloxacin } & \multicolumn{2}{|c|}{ Ciprofloxacin } \\
\hline $\begin{array}{l}\text { No. of Patients } \\
\text { Mean Age } \\
\text { Race: }\end{array}$ & $\begin{array}{l}\text { (n) } \\
\text { (years) }\end{array}$ & $\begin{array}{l}66 \\
24 \cdot 5\end{array}$ & (R: 18-58) & $\begin{array}{l}75 \\
23 \cdot 3\end{array}$ & (R: 17-52) \\
\hline $\begin{array}{l}\text { Chinese } \\
\text { Malay } \\
\text { Indian } \\
\text { Others }\end{array}$ & $\begin{array}{l}(\%) \\
(\%) \\
(\%) \\
(\%)\end{array}$ & $\begin{array}{r}40 \\
12 \\
11 \\
3\end{array}$ & $\begin{array}{r}(60 \cdot 6) \\
(18 \cdot 2) \\
(16 \cdot 7) \\
(4 \cdot 5)\end{array}$ & $\begin{array}{r}43 \\
19 \\
11 \\
2\end{array}$ & $\begin{array}{r}(57 \cdot 3) \\
(25 \cdot 3) \\
(14 \cdot 7) \\
(2 \cdot 7)\end{array}$ \\
\hline \multicolumn{2}{|c|}{$\begin{array}{l}\text { No. of patient with Reactive VDRL } \\
\text { No. of patient with PPNG infection } \\
\text { No. of patient with Non-PPNG infection }\end{array}$} & $\begin{array}{r}3 \\
22 \\
44\end{array}$ & & \multicolumn{2}{|l|}{$\begin{array}{r}3 \\
24 \\
51\end{array}$} \\
\hline
\end{tabular}

Table 2 Overall cure rates with perfloxacin and ciprofloxacin

\begin{tabular}{llll}
\hline & \multicolumn{2}{l}{$N$ gonorrhoeae } & \\
\cline { 2 - 4 } & $\begin{array}{l}\text { PPNG } \\
n(\%)\end{array}$ & $\begin{array}{l}\text { Non-PPNG } \\
n(\%)\end{array}$ & $\begin{array}{l}\text { Overall cure } \\
\text { rate (\%) }\end{array}$ \\
\hline Cured with perfloxacin & $22 / 22(100)$ & $43 / 44(97 \cdot 7)$ & $65 / 66(98 \cdot 5)$ \\
Cured with ciprofloxacin & $23 / 24(95 \cdot 8)$ & $51 / 51(100)$ & $73 / 74(98 \cdot 6)$ \\
\hline
\end{tabular}

were excluded as the urethral cultures were negative for $N$. gonorrhoeae. An additional 12 patients in the perfloxacin group and five in the ciprofloxacin group were excluded from further analysis as they defaulted both posttreatment reviews. Sixty-six in the perfloxacin treatment group and 75 in the ciprofloxacin group were assessible for the study. The clinical and laboratory features of these patients are presented in table 1.

One treatment failure occurred in each treatment group. Pre-treatment urethral cultures isolated non-PPNG in the patient given perfloxacin and PPNG in the other. The overall cure rates with perfloxacin and ciprofloxacin were $98.5 \%$ and $98.6 \%$ respectively (table 2 ).

At the second follow-up visit, 38 of 66 patients $(57 \cdot 6 \%)$ treated with perfloxacin and 37 of 75 patients $(49.3 \%)$ given ciprofloxacin had normal urethral smears on microscopy. However, some of these patients had received antibiotics such as tetracycline and erythromycin at the first follow up visit. After the exclusion of those patients who had received a second course of antibiotics, the rate of postgonococcal urethritis was found to be $64.3 \%$ (27 of 42 ) in the perfloxacin group and $67 \cdot 3 \%$ (37 of 55) in the ciprofloxacin group. The final evaluation is presented in table 3 .

\section{Drug Tolerance}

The drugs were generally well tolerated with adverse effects occurring in a small minority. One patient who received perfloxacin complained of swelling of the lower eyelids lasting 3 hours after ingestion of the drug. Adverse

Table 3 Outcome of patients treated with perfloxacin or ciprofloxacin

\begin{tabular}{lll}
\hline Final Evaluation & $\begin{array}{l}\text { Perfloxacin } \\
n(\%)\end{array}$ & $\begin{array}{l}\text { Ciprofloxacin } \\
n(\%)\end{array}$ \\
\hline Cured & $38(48 \cdot 5)$ & $37(49 \cdot 3)$ \\
Cured with PGU & $27(40 \cdot 9)$ & $36(48 \cdot 0)$ \\
Defaulted & $13(19 \cdot 7)$ & $5(6 \cdot 7)$ \\
Reinfected & $0(0)$ & $1(1 \cdot 3)$ \\
Failed treatment & $1(1 \cdot 5)$ & $1(1 \cdot 3)$ \\
Total no. of patients & $66(100)$ & $75(100)$ \\
\hline
\end{tabular}

Table 4 Antimicrobial susceptibility of 148 isolates of $N$. gonorrhoeae to perfloxacin or ciprofloxacin

\begin{tabular}{|c|c|c|c|}
\hline & \multicolumn{3}{|l|}{$M I C(m g / l)$} \\
\hline & Range & $M I C_{s o}$ & $M I C_{90}$ \\
\hline $\begin{array}{l}\text { Perfloxacin } \\
\text { Ciprofloxacin }\end{array}$ & $\begin{array}{l}0.0005->0.125 \\
0.002->0.125\end{array}$ & $\begin{array}{l}0.0008 \\
0.015\end{array}$ & $\begin{array}{l}0.015 \\
0.03\end{array}$ \\
\hline
\end{tabular}

Table 5 Antimicrobial susceptibility of the 2 isolates of $N$ gonorrhoeae that did not respond to treatment with perfloxacin or ciprofloxacin

\begin{tabular}{lll}
\hline & \multicolumn{2}{l}{$\begin{array}{l}\text { MIC (mgll) of isolates of } N . \text { gonorrhoeae } \\
\text { that failed treatment with }\end{array}$} \\
\cline { 2 - 3 } & Perfloxacin & Ciprofloxacin \\
\hline Perfloxacin & $>0.125$ & - \\
Ciprofloxacin & - & $>0.125$ \\
Penicillin & 0.25 & $>32$ \\
Ampicillin & 0.25 & $>8$ \\
Tetracycline & 8 & 4 \\
Kanamycin & 8 & 8 \\
Streptomycin & 16 & 8 \\
\hline
\end{tabular}

effects attributed to ciprofloxacin in six patients were dryness of the mouth, urticaria, thirst, hunger, genital itch in the absence of a rash and an increase in the frequency of asthmatic attacks in the week following ingestion of the drug.

\section{Antimicrobial susceptibility of $N$. gonorrhoeae} One hundred and forty-six isolates of $N$. gonorrhoeae were tested for beta-lactamase production and susceptibilities to either perfloxacin or ciprofloxacin, and, penicillin, ampicillin, tetracycline, kanamycin and spectinomycin.

The MICs of perfloxacin and ciprofloxacin for $50 \%$ and $90 \%$ of the isolates are presented in table 4. The antibiograms for the two isolates resulting in infection not eradicated with the test medication are shown in table 5.

Forty-seven $(32 \cdot 2 \%)$ of the isolates were penicillinase producing. Penicillin resistance (MIC $\geqslant 1 \mathrm{mg} / \mathrm{l})$ was seen in 89 of $146(61 \%)$ isolates, $42(47 \%)$ of which were non-PPNG.

Only a single isolate showed susceptibility to tetracycline at $0.5 \mathrm{mg} / \mathrm{l}$. The rest $(99.32 \%)$ were resistant to tetracycline at $\geqslant 2 \mathrm{mg} / \mathrm{l}$. High level tetracycline resistance (MIC $\geqslant 16 \mathrm{mg} / \mathrm{l}$ ) was present in 11 of $146(7.4 \%)$ isolates. Thirty-two isolates of non-PPNG $(21.9 \%$ of 146) were resistant to penicillin and tetracycline at $\geqslant 2 \mathrm{mg} /$, indicating chromosomally mediated resistance (CMRNG).

Kanamycin resistance (MIC $\geqslant 32 \mathrm{mg} / \mathrm{l}$ ) was seen in 20 of $146(13.7 \%)$ isolates. No invitro resistance to spectinomycin (MIC $\geqslant 128 \mathrm{mg} / \mathrm{l}$ ) was detected.

\section{Discussion}

The successful eradication of gonococcal infections with the fluoroquinolones has been well documented in the literature. The majority of the reports were on the use of single-dose ciprofloxacin therapy which achieved cure rates of up of $100 \% .9$ Other fluoroquinolones used with somewhat lower efficacy include norfloxacin, ofloxacin and enoxacin. The cure 
rates of $98.5 \%$ and $98.6 \%$ with perfloxacin and ciprofloxacin in our study are comparable to those of the above reports. As such, the recommendation that either of these drugs be used as first-line therapy for uncomplicated gonococcal urethritis in males appear to be amply justified. The oral route of administration offers an added advantage over the use of drugs such as ceftriaxone and spectinomycin which necessitate parenteral administration.

The high rates of post-gonococcal urethritis $64.3 \%$ and $67.3 \%$ for the perfloxacin and ciprofloxacin groups respectively) in our study provide some cause for concern. A previous local study ${ }^{10}$ had documented a rate of $48 \cdot 8 \%$ in men after treatment of gonorrhoea with spectinomycin. In view of these findings, we would recommend the institution of routine treatment for post-gonococcal urethritis at first presentation for gonococcal urethritis, a practice which has not gained widespread acceptance in this part of the world.

In a review of data gathered from studies on penicillin susceptibility of $N$. gonorrhoeae, countries in South East Asia have been found to have the highest percentage of strains with reduced susceptibility. ${ }^{11}$ The percentage of PPNG in the region has been reported to be in the range of $17 \cdot 8$ to $44.4 \% .^{10}{ }^{12}{ }^{13}$ We found $32.6 \%$ of PPNG among our isolates. Although chromosomal analysis was not performed, there was evidence of chromosome mediated resistance (CMRNG) in $21.9 \%$ of the isolates. The inference was based on the finding of MICs of penicillin and tetracycline of $\geqslant 2.0 \mathrm{mg} / \mathrm{l}$ in strains without plasmid mediated resistance. ${ }^{14}$

The gonococci isolated in the region are also relatively resistant to other common antibiotics. In 1981, Brown et $a^{12}$ found tetracycline resistance at MIC $\geqslant 2.0 \mathrm{mg} / \mathrm{l}$ in $70.1 \%$ of gonococcal isolates in Bangkok. In our more recent study, we were able to document the same level of in-vitro tetracycline resistance in $99.3 \%$ of the isolates. In addition, $7 \cdot 4 \%$ demonstrated high level tetracycline resistance (MIC $\geqslant 16 \mathrm{mg} / \mathrm{l}$ ) which is most probably plasmid mediated (TRNG). Although tetracyclines have long ceased to be used in the treatment of gonorrhoea in this region, it has been postulated that their use in chlamydial infections and pelvic inflammatory disease probably assist the establishment of TRNG. ${ }^{15}$

The disturbing spectre of fluoroquinolone resistance in gonococci has done much to dampen the initial enthusiasm in the use of these drugs. Turner et al reported an isolate of penicillinase-negative chromosomally mediated resistant strain of $N$. gonorrhoeae (CMRNG) with an MIC of $0.1 \mathrm{mg} / 1$ for ciprofloxacin. ${ }^{16}$ The strain was isolated from a man on his return to the UK from Thailand.
Later reports of reduced susceptibility of $N$ gonorrhoeae to ciprofloxacin found MICs of up to $0.5 \mathrm{mg} / 1 .{ }^{17}$ Ciprofloxacin-resistant strains of gonococci with an MIC of $1.0 \mathrm{mg} / \mathrm{l}$ have apparently been isolated in the United States. ${ }^{18}$ It has been shown that strains resistant to one fluoroquinolone have increased resistance to other fluoroquinolones as well. ${ }^{19}$ Given the ease of travel to and from Singapore and her location within a region reputed to have high gonococcal antimicrobial resistance, the fluoroquinolones may well be doomed to outlive their usefulness as anti-gonococcal agents even before their widespread local use for this purpose.

The authors thank Rhone-Poulenc (Singapore) Pte Ltd for providing the perfloxacin and Bayer (Singapore) Pte Ltd, the ciprofloxacin, and Mdm Kalsom Wadinshah for preparation of the manuscript.

1 James DG. Therapeutic focus: The fluoroquinolones. $\mathrm{Br} \mathcal{F}$ Clin Pract 1989;43:66-7.

2 Loo PS, Ridgway GL, Oriel JD. Single dose ciprofloxacin or treating gonococcal infections in men. Genitourin Med 1985;61:302-5.

3 Shahmanesh M, Shukla SR, Phillips I, et al. Ciprofloxacin for treating urethral gonorrhoea in men. Genitourin Med 1986;62:86-7.

4 Lassus A, Karppinen L, Ingervo L, et al. Ciprofloxacin vs amoxycillin and probenecid in the treatment of uncomplicated gonorrhoea. Scand $\mathcal{F}$ Infect Dis, Suppl. 1989;60 58-61.

5 Bryan JP, Hira SK, Luo Nkandu, et al. Oral ciprofloxacin v ceftriaxone for the treatment of urethritis from resistan N. gonorrhoeae in Zambia. Antimicrob Agents Chemother $1990 ; 34: 819-22$.

6 Ball M, Kanga JM, Meilo $\mathrm{H}$, et al. Treatment of acute gonococcal urethritis in men with a single-dose of $800 \mathrm{mg}$ perfloxacin. Br 7 Clin Pract 1990;44:140-1.

7 Sng EH, Yeo KL, Rajan VS. Simple method for detecting penicillinase-producing $N$. gonorrhoeae and Staphylococcus penicilinase-producing N. gonorrhoeae a

8 Sng EH, Rajan VS, Pang R, Yeo KL. Susceptibility of $N$ gonorrhoeae to cefotaxime and ceftizoxime. $\mathrm{Br} \mathcal{F}$ Venereal Dis $1981 ; 57: 162-4$

9 Paton JH, Reeves DS. The fluoroquinolone antibiotics: microbiology, pharmacokinetics and clinical use. Drugs 1988;36:193-228.

10 Chan RKW, Thirumoorthy T, Sng EH, Nadarajah M. A comparison between aztreonam and spectinomycin in the treatment of uncomplicated gonorrhoea in males. Venereology 1991;4:60-2.

11 Sng EH, Lim AL, Yeo KL. Susceptibility to antimicrobials of $\boldsymbol{N}$. gonorrhoeae isolated in Singapore: implications on the need for more effective treatment regimens and control strategies. Br ₹Venereal Dis 1984;60:374-9.

12 Brown S, Warnnissorn T, Biddle J, et al. Antimicrobia resistance of $N$. gonorrhoeae in Bangkok: Is single-drug treatment passe. Lancet 1982;ii:1366-8.

13 Utoro D, Lumintang H, Barakbah J, et al. The prevalence of gonorrhoea and PPNG in two different socio-economic levels of prostitute areas in Surabaya. Proceedings of the 7th IUVDT Regional Conference on the Sexually Transmitted Diseases, September 1991.

14 Faruki H, Kohmeseher RN, McKinney WP, et al. A community based outbreak of infection with penicillinresistant $N$. gonorrhoeae not producing penicillinase (chromosomally mediated resistance). $N$ Engl f Med 1985; 313:607-11.

15 Easmon CSF. The changing pattern of antibiotic resistance of N. gonorrhoeae. (Editorial) Genitourin Med 1990 of $N$. $g$.

16 Turner A, Jephcott AE, Haji TC, et al. Ciprofloxacin resistant $N$ gonorrhoeae in the UK Genitourin Med 1990;66:43-6.

17 Jephcott AE, Turner A. Ciprofloxacin resistance in gonococci. Lancet 1990;335:165.

18 Holmes KK (unpublished data) Centre for AIDS and STD University of Washington, USA, 1991.

19 Smith JT. The mode of action of 4-quinolones and possible mechanisms of resistance. 7 Antimicrob Chemother 1986; 18 Suppl. D:21-9. 
ment. Planning erotic times and fostering anticipation contributes to enhanced activity, whatever the chosen setting. Making time for leisurely pursued non-penetrative sex is commended as a must for young novice lovers, bored old lovers seeking to extend their repertoire as well as those seeking to rekindle old intimacies. Bathing together and practising the pleasures to be found in tactile communication such as fondling and massage (frotting is not mentioned) are next emphasised. Tactile communication is further explored in terms of kissing or its subsidiaries of sucks, bites, wetting and blowing. Few nuances are neglected.

And so we move on to detailed illustration and discussion of the variations of fellatio, cunnilingus (no mention of the Oriental variety) and mutual masturbation. Here the need to be constantly aware of each other's wants, both physical and emotional, calls for careful consideration. The need is to reflect each other emotionally. Finally it is made clear that experimenting with all positions for intercourse alone can lead couples to agreeing rationally a selection of their favourites. We are left in no doubt that the highest degrees of sexual pleasure lie in the art of giving and surrendering to one another.

Dr Stanway's Lovers' Guide II complements his No. I. They can be recommended to young and old alike. The British Board of Film Classification authorises their purchase and viewing by 18 year olds. They are available on the counters in High Street shops.

In an age when sex education is compulsory in our schools and "The Health of the Nation, 1992"' calls for priority targetting of Sexual Health, the publication of these guides is brilliantly supportive. They cannot do other than augment the endeavours of all involved in seeking safer and saner sex.

RS MORTON

1 The Health of the Nation. A Strategy for Health in England. London HMSO, 1992. pp in Englan.

\section{NOTICE}

The Pathological Society of Great Britain \& Ireland at the Queen Elizabeth Conference Centre, London

Wednesday 6 January 1993: Symposium. Diarrhoeal disease: current concepts $\mathcal{E}$ future challenges (Fointly with Royal Society of Tropical Medicine $\mathcal{E}$ Hygiene and US Navy Medical Research Unit 3).

Thursday 7 January 1993: Symposium. New Developments in sexually-transmitted diseases (Fointly with the STD Discussion Group) This symposium will be followed by a free paper session on Thursday afternoon 7 fanuary.

For further details contact: Mrs J E Edwards, Pathological Society of Great Britain \& Ireland, 2 Carlton House Terrace, London SW1Y 5AX, UK. Tel: 071-976 1260. Fax: 071-976 1267.

\section{Correction}

In the letter by James, Gilles, and Bignell HIV testing in genitourinary medicine-sustained increased demand in 1991 (Genitourin Med $1992 ; 68: 275)$ the figure was mistakenly omitted. It is here reproduced.

\section{Number Of IMV-1 Antibody Test - GU Medicine Depertment}

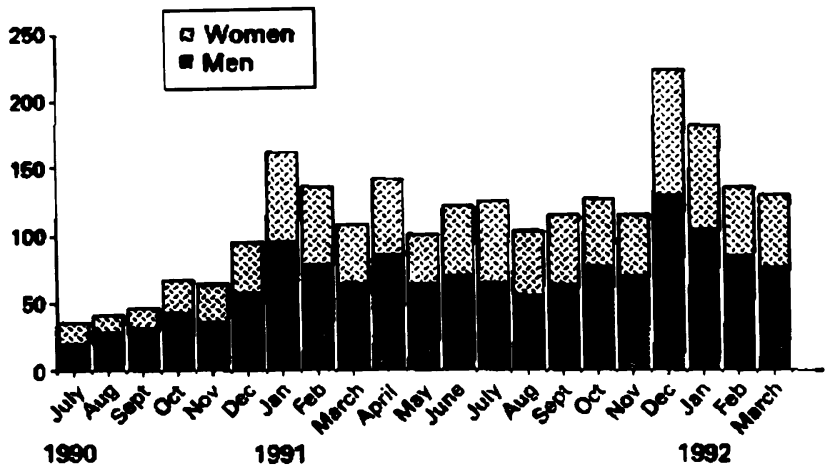

Figure The number of HIV tests in a genitourinary medicine from fuly 1990 to March 1992.

\section{Correction}

In the article by Cheong, Chan, Nadarajah (Genitourin Med 1992;68:260-262) pefloxacin was mis-spelled perfloxacin in the title and in the text. 